\title{
Antioxidants, antimicrobial and cytotoxic potential of Swertia chirata.
}

\author{
Muhammad Atif Khan', Muhammad Zia ${ }^{2}$, Muhammad Arfan', Abdul Nazir', Nighat Fatima', \\ Muhammad Naseer $^{5}$, Shujaat Ali Khan ${ }^{1}$, Tariq Ismail ${ }^{1}$, Yasser MSA Alkahraman ${ }^{1}$, Ghulam Murtaza ${ }^{6 *}$, \\ Abdul Mannan ${ }^{*}$ \\ ${ }^{1}$ Department of Pharmacy, COMSATS University Islamabad (Abbottabad Campus 22060), Pakistan \\ ${ }^{2}$ Department of Biotechnology, Quaid-i-Azam University, Islamabad, Pakistan \\ ${ }^{3}$ Department of Chemistry, School of Natural Sciences, National University of Science and Technology, Islamabad, \\ Pakistan \\ ${ }^{4}$ Department of Environmental Science, COMSATS Institute of Information Technology, Abbottabad, Pakistan \\ ${ }^{5}$ Department of Environmental Science, International Islamic University, Islamabad, Pakistan \\ ${ }^{6}$ Department of Pharmacy, COMSATS University Islamabad (Lahore Campus), Pakistan
}

\begin{abstract}
The current study was designed to evaluate the properties of various fractions of methanolic extract prepared from aerial parts of $S$ wertia chirata. Five fractions, RA-78, RA-91, RA-112, RA-14 and RA-15 showed significantly high DPPH scavenging capacity. In finding out antimicrobial activities, different fractions have shown mild activities against Bordetella bronchiseptica and Micrococcus luteus, while all fractions showed significant results against Aspergillus fumigatus followed by Mucor species and five fractions were active against Aspergillus niger. In measurement of brine shrimp cytotoxic potential of different fractions, three fractions RA-12, RA-34 and RA-78 had shown the best cytotoxic results with zero $\mathrm{LD}_{50}$. In determining antileishmanial properties of different fractions, the best results were exhibited by fraction RA-78 and RA-112 with zero percent survival of Leishmania parasite. Various fractions of methanolic extract prepared from aerial parts of $S$ wertia chirata promisingly possess antioxidant, antimicrobial, brine shrimp cytotoxic, and antileishmanial activities.
\end{abstract}

Keywords: Swertia chirata, Phytochemical evaluation, DPPH free radical scavenging activity, Antimicrobial properties, Cytotoxicity assay, Antileishmanial activity.

\section{Introduction}

Medicinal plants are as assumed as major source for active constituents which are used for development of drugs. There are about half million plants around the world, and most of their medicinal activities have not explored yet [1]. According to $\mathrm{WHO}$, about $80 \%$ of world population relies on plant based conventional medicines especially for their primary health care need [2]. It was a common perception on the basis of tradition, that there is no harm in the uses of natural medicinal plants [3].

The medicinal plant Swertia chirata (Roxb.) Buch-Ham. ex C. B. Clarke belongs to the family gentianaceae. Its folk use names are Chirata, Chareta, and chirayta. It is being used in different remedies as antipyretic and anthelmintic [4] and in arthritis [5]. It is also used for gastrointestinal and urogenital tract disorders [4]. This plant is also being used traditionally for treatment of cancer [6].
The objectives of present study were to prepare crude methanolic extract and its different fractionations obtained from the aerial parts of Swertia chirata and evaluate their phytochemical, antioxidant, antimicrobial, cytotoxic, and antileishmanial potential.

\section{Materials and Methods}

\section{Extract preparation and its fractionation}

Swertia chirata plant material was collected from Galyat region of Khyber Pakhtunkhwa, Pakistan and identified by the taxonomist and verified by comparing with available literature and herbarium specimens. The specimen was deposited in the herbarium and given the voucher number "PAC1009".

The aerial parts of the plant material were shade dried, crushed into fine powder. The powdered plant material $(4.3 \mathrm{~kg})$ was macerated in methanol $(10 \mathrm{~L})$ for $10 \mathrm{~d}$. Methanolic extract was 
filtered through muslin cloth and filter paper and dried under reduced pressure for further analysis.

Fractionation of methanolic extract (RA-16) was carried out by using gravity column chromatography. For column packing, slurry of silica gel (400 g) prepared in chloroform was poured into it, chloroform was further added with continuous tapping to develop the column and methanolic extract was applied slowly on the top. The solvent systems of $5 \% \mathrm{CH}_{3} \mathrm{OH} /$ $\mathrm{AHCl}_{3}-10 \%, 15 \%$, and $20 \% \mathrm{CH}_{3} \mathrm{OH} / \mathrm{AHCl}_{3}$ were run and different fractions were collected, labeled as RA-12, RA34, RA-56, RA-78, RA-91, RA-112, RA-13, RA-14, and RA-15.

\section{Total phenolic and flavonoid contents}

The procedure used to determine the total phenolic contents, using Folin-Ciocalteu reagent [7]. The absorbance of reaction mixture was recorded at $715 \mathrm{~nm}$. Gallic acid was used as standard and total phenolic contents were express as gallic acid equivalent. In addition, the method utilized for evaluation of total flavonoid contents was aluminium chloride colorimetric method [8]. The absorbance of the reaction mixture was taken at $415 \mathrm{~nm}$. Quercetin was used as a standard and flavonoid contents were expressed as quercetin equivalent. The experiments were repeated in triplicate.

\section{DPPH radical-scavenging activity}

The antioxidant activities of crude methanolic extract and its fractions were determined by using DPPH free radical scavenging assay, as described previously [9]. The absorbance was taken at $517 \mathrm{~nm}$ by micro plate reader and scavenging percentage was calculated. The experiment was performed in triplicate. Ascorbic acid was used as a positive control, whereas methanol was used as a negative control.

\section{Antimicrobial assay}

The antibacterial activity of each fraction was determined by using disc diffusion method [10] using three strains of bacteria. One strain Micrococcus luteus was gram-positive while two strains Bordetella bronchiseptica and Salmonella typhi were gram-negative. The inoculum of each bacterium was spread smoothly on surface of sterilized solidified nutrient agar media present in the petri plate. Then $5 \mu$ of each fraction was loaded on autoclaved filtered paper discs and placed on the respective places in the petri plates. Each plate contained two disc of positive and one disc of negative control. The plates were incubated at $37^{\circ} \mathrm{C}$ for about $24 \mathrm{~h}$. The zone of inhibition (mm) was measured and assay was performed in duplicate.

The antifungal activity of each plant fraction was evaluated by using disc diffusion method [11]. Three different fungal strains were used, which were Mucor specie, Aspergillus fumigates, and Aspergillus niger. After solidification of sterilized sabouraud dextrose agar media in the petri plate, inoculum of each fungus was swabbed on its surface to produce the lawn. Then $5 \mu \mathrm{l}$ of each fraction was loaded on filter paper disc and each disc was placed on its respective place in labeled plate. Each plate contains two disc of positive and one disc of negative control. The plates were then incubated at $28^{\circ} \mathrm{C}$ for 24 h. After incubation, zones of inhibition were measured and experiment was performed in triplicate.

\section{Brine shrimp lethality assay}

The cytotoxic effects of all fractions were measured by using brine shrimp lethality bioassay [8]. Three concentrations of each fraction $(1000 \mu \mathrm{g} / \mathrm{ml}, 100 \mu \mathrm{g} / \mathrm{ml}$, and $10 \mu \mathrm{g} / \mathrm{ml})$ and three concentrations of standard drug were prepared $(10 \mu \mathrm{g} / \mathrm{ml}, 1$ $\mu \mathrm{g} / \mathrm{ml}$, and $0.1 \mu \mathrm{g} / \mathrm{ml}) .96$ plate was used for this assay and 250 $\mu l$ of sea water was added to the well so that the sample was dissolved in the sea water. Then 10 shrimps (Artemisa salina) were transferred to each well. The volume of the wells was raised up to $300 \mu \mathrm{l}$ to attain desired concentration of each well. The plates were incubated for $24 \mathrm{~h}$ at room temperature. Then shrimps were taken from each well and counted the survivors under magnifying glass. The lethal dose of crude fractions against brine shrimps was calculated by using Finny software.

\section{Antileishmanial assay}

Pre-established Leishmania tropica KWH23 strain was incubated at $24 \pm 1^{\circ} \mathrm{C}$ for $6-7 \mathrm{~d}$ in 199 medium containing $10 \%$ fetal bovine serum. The in vitro antileishmanial assay was performed according to the protocol previously described previously [12] with a slight modification. Stock solution of each fraction $(4,000 \mathrm{ppm})$ was prepared by dissolving $4 \mathrm{mg}$ in $1000 \mu \mathrm{L}$ of distilled water. The stock solutions were serially diluted in 96 well plates. Positive and negative control was Amphotericin B and distilled water, respectively. The microtiter plates were incubated at $24^{\circ} \mathrm{C}$ for $72 \mathrm{~h}$. The experiment was performed in triplicate. After $72 \mathrm{~h}$, about $15 \mu \mathrm{l}$ of test culture were then transferred to improved neubauer counting chamber and live promastigotes were counted under light microscope. For $\mathrm{LC}_{50}$ calculation, probit regression analysis of SPSS Ver. 21 was used.

\section{Results and Discussion}

\section{Total phenolic and flavonoid contents}

According to results of fractions and crude methanolic extract of Swertia chirata, high total phenolic contents were found in four fractions, RA-15, RA-13, RA-34 and RA-14 (8.61 \pm 0.08 , $7.92 \pm 0.07,7.16 \pm 0.51$ and $7.16 \pm 0.06 \mu \mathrm{g} \mathrm{EQ} / \mathrm{mg}$ respectively) (Figure 1). Similar range of total phenolic contents was found in Polygonatum species [13]. Moreover, these concentrations may depend on variation in collection time and site [14]. High total flavonoid contents (Figure 1) were found in three fractions, RA-56, RA-78 and RA-34 $(232.5 \pm 7.4,118.855 \pm 3.5$ and $93.185 \pm 3.2 \mu \mathrm{g} \mathrm{EQ} / \mathrm{mg}$, respectively). The highest total flavonoid contents were found in the fraction RA-56 followed by RA-78 and RA-34. These concentrations of total flavonoid contents present in the plant were higher than that present in Torilis leptophylla [15]. 


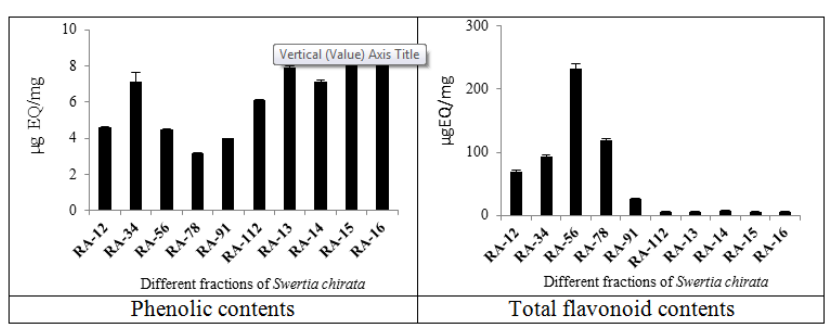

Figure 1. Phytochemical analysis of Swertia chirata.

\section{DPPH radical-scavenging activity}

All fractions showed statistically significant $(\mathrm{P}<0.05) \mathrm{DPPH}$ scavenging capacities (\%). DPPH scavenging activity (Figure 2) of five fractions RA-78, RA-91, RA-112, RA-14, and RA-15 had shown significantly $(\mathrm{P}<0.05)$ high scavenging potential $(74.3 \pm 3.4 \%, 85.77 \pm 2.49 \%, 77.17 \pm 2.1 \%, 85.29$ $\pm 2.61 \%$ and $78.81 \pm 2.1 \%$, respectively). RA-91 fraction showed $10.4 \%$ more potential with respect to extract, showing significantly $(\mathrm{P}<0.05)$ higher antioxidant potential. As compared to DPPH results of Thymus serpyllum, it was found that methanolic extract of plant showed better antioxidant results then the aqueous and n-hexane plant extract [16].

\section{Antimicrobial assay}

All fractions did not show any activity (Table 1) against Salmonella typhimurium. However, RA-112, RA-13, RA-14, RA-15 and RA-16 were active against Micrococcus luteus. The encouraging activities were shown by all fractions against Bordetella bronchiseptica. These results are contrary to the results in which methanolic extract prepared from bark, fruits and leaves of Ficus microcarpa was used and high antibacterial activity was reported [17].

Five fractions (RA-78, RA-91, RA-112, RA-13, and RA-14) were slight active against Aspergillus niger (Table 1). However, all fractions have shown significantly $(\mathrm{P}<0.05)$ results against Mucor species where RA-56 showed highest inhibition followed by RA-91. Comparative fungal growth inhibition cause by all fractions against Aspergillus fumigatus was highest. Fraction RA-14 showed highest growth inhibition in the present antifungal study. Our results are better than those published in another study performed previously [16].

Table 1. Antibacterial and antifungal activity of crude extract and its fractions.

\begin{tabular}{|c|c|c|c|c|c|c|}
\hline \multirow[t]{2}{*}{ Sample code } & \multicolumn{6}{|c|}{ Zone of inhibition (mm) } \\
\hline & S. typhi & M. luteus & B. septica & A. niger & Mucor Sp. & A. fumigatus \\
\hline RA-12 & 0 & 0 & 6.5 & 0 & $14 \pm 1.41$ & $13 \pm 1.41$ \\
\hline RA-34 & 0 & 0 & 6 & 0 & $10.5 \pm 0.71$ & $10 \pm 2.83$ \\
\hline RA-56 & 0 & 0 & 6 & 0 & $16 \pm 1.41$ & $11 \pm 1.41$ \\
\hline RA-78 & 0 & 0 & 6 & $7 \pm 0.15$ & $13 \pm 1.41$ & $7 \pm 0$ \\
\hline RA-91 & 0 & 0 & 6 & $7 \pm 0.17$ & $14.25 \pm 3.18$ & $10 \pm 0$ \\
\hline RA-112 & 0 & 6 & 6 & $7 \pm 0.19$ & $9 \pm 1.41$ & $6 \pm 0$ \\
\hline RA-13 & 0 & 6 & 6 & $7 \pm 0.21$ & $15 \pm 4.24$ & $9 \pm 1.41$ \\
\hline RA-14 & 0 & 6 & 6 & $7 \pm 0.21$ & $15.5 \pm 0$ & $21 \pm 1.41$ \\
\hline RA-15 & 0 & 7 & 6 & 0 & $10 \pm 0$ & $8 \pm 2.83$ \\
\hline RA-16 & 0 & 6 & 6 & 0 & $10.5 \pm 4.95$ & $14.5 \pm 0.71$ \\
\hline Control (Cefotaxime/terbinafine) & 23 & 21 & 17 & $33 \pm 1.52$ & $30 \pm 1.0$ & $30 \pm 1.52$ \\
\hline
\end{tabular}

\section{Brine shrimp lethality assay}

In brine shrimp lethality assay, $\mathrm{LD}_{50}$ value lower than 1000 $\mu \mathrm{g} / \mathrm{ml}$ is considered cytotoxic [18]. Three fractions RA-12, RA-34 and RA-78 showed the best cytotoxic results with zero $\mathrm{LD}_{50}$. The other significant results were obtained by the fraction RA-13 with $16.54 \mu \mathrm{g} / \mathrm{ml} \mathrm{LD}_{50}$ and by fraction RA-112 with $17.37 \mu \mathrm{g} / \mathrm{ml} \mathrm{LD}_{50}$ (Table 2). On correlation of our work with brine shrimp lethality of Artemisia dubia extract, our all fractions showed encouraging cytotoxic activities [8].

Table 2. Results of brine shrimp lethality assay.

\begin{tabular}{lllll}
\hline Sample code & \multicolumn{4}{c}{ Brine shrimp lethality assay (percentage death) } \\
\cline { 2 - 5 } & $\mathbf{1 0 0 0} \boldsymbol{\mu g} / \mathbf{m l}$ & $\mathbf{5 0 0} \boldsymbol{\mu g} / \mathbf{m l}$ & $\mathbf{2 5 0} \boldsymbol{\mu g} / \mathbf{m l}$ & LD $_{50} \boldsymbol{\mu g} / \mathbf{m l}$ \\
\hline RA-12 & 43 & 35 & 23 & 0 \\
\hline RA-34 & 23 & 20 & 10 & 0 \\
\hline RA-56 & 53 & 33 & 13 & 901.2 \\
\hline RA-78 & 33 & 25 & 15 & 0 \\
\hline RA-91 & 60 & 56 & 53 & 92.91 \\
\hline RA-112 & 96 & 83 & 73 & 17.37 \\
\hline
\end{tabular}




\begin{tabular}{lllll}
\hline RA-13 & 96 & 86 & 77 & 16.54 \\
\hline RA-14 & 86 & 80 & 75 & 69.5 \\
\hline RA-15 & 100 & 70 & 56 & 144.94 \\
\hline RA-16 & 100 & 73 & 50 & 249.52 \\
\hline Doxorubicin & 100 & 85 & 70 & 1.98 \\
\hline
\end{tabular}

\section{Antileishmanial activity}

All fractions were also subjected to antileishmanial activities and found positive against leishmaniasis disease (Figure 3). The best results were shown by fraction RA-78 and RA-112 with $0 \%$ survival of Leishmania parasite. The second best results were shown by fractions RA-16 and RA-91 by $12 \%$ survival rate. Amphotericin-B used as a standard drug against Leishmania protozoa. The results of current study were quite better than the previous work done by in vitro assessment of anticutaneous leishmaniasis activity of Sudanese plants $[19,20]$.

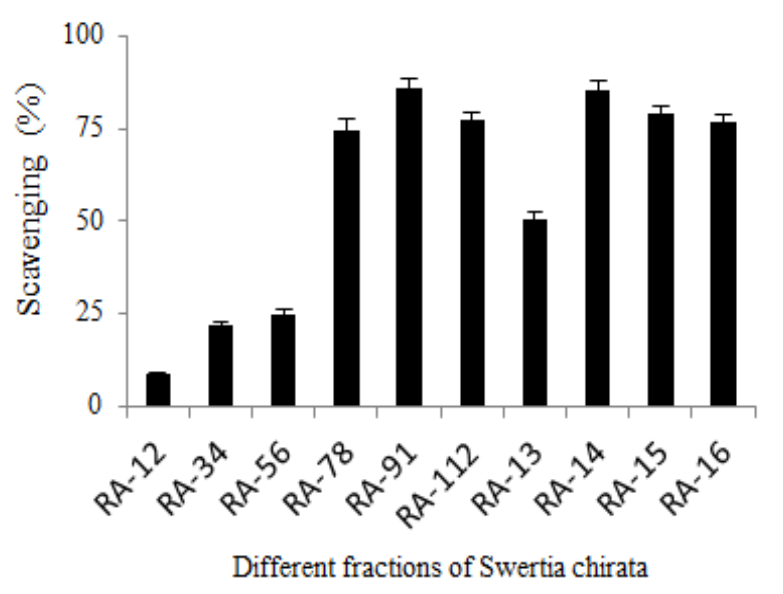

Figure 2. DPPH scavenging assay of various fractions of crude methanolic extract.

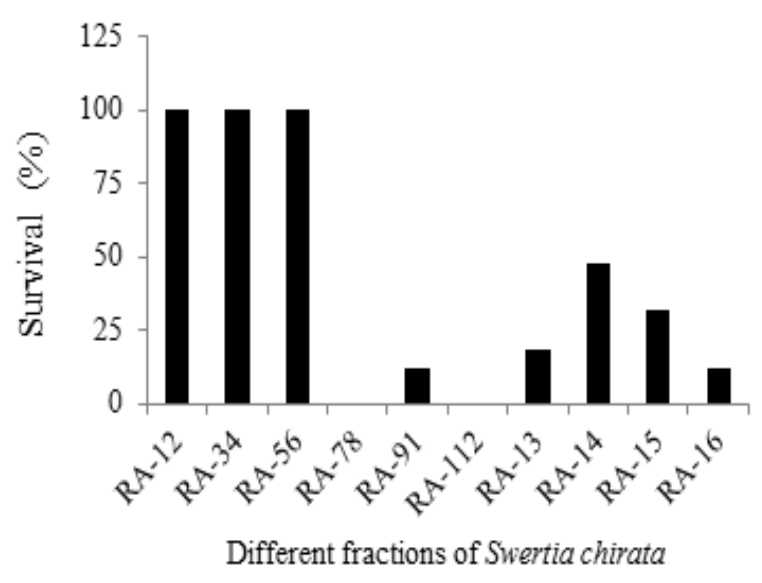

Figure 3. Antileishmanial activity of different fraction of Swertia chirata.

\section{Conclusion}

It can be concluded that various fractions of methanolic extract prepared from the aerial parts of Swertia chirata promisingly possess various chemical and biological properties including antioxidant, antimicrobial, brine shrimp cytotoxic, and antileishmanial activities.

\section{References}

1. Bassam ARH. Medicinal plants (Importance and uses). Pharm Anal Acta 2012; 3: 4172.

2. Boon E, Ahenkan A. Impact of deforestation on medicinal plants in Ghana 2008.

3. Haq I safety of medicinal plants. Pak J Med Res 2004; 43: 1-8.

4. Tabassum S. An overview of medicinal importance of Swertia chiraytia. Int J Appl Sci Technol 2012; 2: 298-304.

5. Kacker S, Chirata S, Sanctum O. Rheumatoid arthritis, phenylbutazone, dexamethasone. A study on the activity of Swertia chirata and Scimum Sanctum in animal model of arthritis. J Evol Med Dent Sci 2013: 1311-1317.

6. Verma KV, Khomendra KS, Kumar A, Zaman K. Comparison of hepatoprotective activity of Swertia chirayita and andrographis paniculata plant of North-East India against $\mathrm{CCl} 4$ induced hepatotoxic rats. J Pharm Res 2013; 7: 647-653.

7. Clarke G, Ting K, Wiart C, Fry J. High Correlation of 2, 2-Diphenyl-1-Picrylhydrazyl (DPPH) radical scavenging, ferric reducing activity potential and total phenolics content indicates redundancy in use of all three assays to screen for antioxidant activity of extracts of plants from the Malaysian rainforest. Antioxidants 2013; 2: 1-10.

8. Haq I. Antibacterial activity and Brine shrimp toxicity of Artemisia dubia extract. Paki J Botany 2012; 44: 1487-1490.

9. Lin YW. Free radical scavenging activity and antiproliferative potential of Polygonum cuspidatum root extracts. J Nat Med 2010; 64: 146-152.

10. Zaidi MA, Sidney AC. Biologically active traditional medicinal herbs from Balochistan, Pakistan. J Ethnopharmacol 2005; 96: 331-334.

11. Manavathu EK. A comparative study of the postantifungal effect (PAFE) of amphotericin B, triazoles and echinocandins on Aspergillus fumigatus and Candida albicans. J. Antimicrob Chemother 2004; 53: 386-389.

12. Ma Y. Activity of dihydroartemisinin against Leishmania donovani both in vitro and vivo. Chin Med J 2004; 117 : 1271-1273.

13. Huang WY. Comparative analysis of bioactivities of four Polygonum species. Planta Medica 2008; 74: 43-49.

14. Djeridane A. Antioxidant activity of some Algerian medicinal plants extracts containing phenolic compounds. Food Chem 2006; 97: 654-660.

15. Saeed N, Muhammad RK, Shabbir M. Antioxidant activity, total phenolic and total flavonoid contents of 
whole plant extracts Torilis leptophylla L. BMC Complement Altern Med 2012; 12: 221.

16. Rehman A. Biological evaluation of wild Thyme (Thymus serpyllum). Pharm Biol 2009; 47: 628-633.

17. Ao C. Evaluation of antioxidant and antibacterial activities of Ficus Microcarpa L. Fil. extract. Food Control 2008; 19: 940-948.

18. Krishnaraju AV, Tayi VNR, Dodda S, Mulabagal V. Biological screening of medicinal plants collected from Eastern ghats of India using Artemia salina ( Brine shrimp test ). Int J Appl Sci Eng 2006; 4: 115-125.

19. MacLaughin JL, Chnag CJ, Smith DL. Bench-top bioassays for the discovery of bioactive natural product. Atta Ur-Rahman. Elsevier Science Publisher B.V. Amsterdam 1991; 10-103.
20. Fatima KA, Nazar AM, Husam M, Abdalla MT, Mubark M, Magzoub, Siddig MA. In vitro Assessment of anticutaneous leishmaniasis activity of some Sudanese plants. Acta Parasitol Turc 2005; 29: 3-6.

\section{*Correspondence to}

Abdul Mannan

Department of Pharmacy

COMSATS University

Abbottabad Campus

Pakistan 